\title{
HANNA ARENDT: LAS IDEOLOGÍAS Y LA SUPRESIÓN DE LA POLÍTICA
}

\section{HANNAH ARENDT: IDEOLOGIES AND THE SUPPRESION OF POLITICS}

\author{
BORJA LUCENA GÓNGORA \\ UNED
}

RESUMEN: El presente artículo procura aclarar, a través del pensamiento de la pensadora judía Hannah Arendt, algunas notas características de las ideologías, entendidas éstas como formas específicamente contemporáneas y novedosas de pensamiento acerca de la realidad y el lugar de los hombres en ella. Partiendo de la actualidad de las ideologías y su hegemonía en el ámbito de lo político, se trata de mostrar cómo su predominio, lejos de una intensificación, conduce a la cancelación de la dimensión política de la vida humana, y cómo este resultado se desprende del contenido mismo y la lógica interna del pensamiento ideológico, y no de circunstancias ocasionales. De acuerdo con esto, se exponen e intentan comprender las categorías nucleares que conforman a las ideologías como genuinas suplantadoras de la acción política: realidad, lógica, libertad, verdad.

\section{Palabras Clave: Hannah Arendt, ideología, política, totalitarismo}

ABSTRACT: This article tries to clarify some features of ideology from the point of view of Hanna Arendt's conception of politics. Ideologies, as understood by Arendt, relate to specific and novel contemporary ways of thinking about reality and man's place in it. If we look at the hegemony of ideology throughout the $20^{\text {th }}$ century, we can acknowledge that its predominance produces not intensification but rather a repudiation of the political dimension of human life. Hannah Arendt contemplates this repudiation as the internal and essential aim of ideologies, not just an occasional circumstance. Accordingly, the article outlines the main categories that constitute ideology as a substitute for political action: reality, logic, freedom, truth.

KEYWORDS: Hannah Arendt, ideology, politics, totalitarianism 


\section{Actualidad de la ideología}

A la hora de ofrecer una breve semblanza de su biografía, Hannah Arendt indicó dos encuentros que marcaron de modo esencial los derroteros de toda su trayectoria vital y, de manera más precisa, la búsqueda y desvelos intelectuales alojados en sus obras; el primero fue el encuentro con la filosofía de la existencia desarrollada de maneras diversas por sus profesores Jaspers y Heidegger; el segundo fue el encuentro crucial con el ascenso y toma del poder por parte de Hitler y el movimiento nacional-socialista, que inauguró su experiencia de una forma enteramente novedosa y terrible de dominación política, el totalitarismo ${ }^{1}$. Cualquier acercamiento a la obra de la autora enseña con evidencia lo verdadero que es en ella el vínculo entre las ideas, los hechos y la experiencia de éstos, y lo urgente que para ella es alcanzar a comprender esa realidad nueva - para la que no encuentra categorías en el seno del pensamiento político tradicional- que emerge a lo largo de sus años de formación y termina por expulsarla de Alemania para condenarla a la condición incierta de judía apátrida. Su intento de comprensión de esa moderna conformación de la política surge de la urgencia existencial de reconciliación con un mundo en el que se ha realizado lo más hostil, y la fuente fundamental de esta hostilidad de la política hacia los hombres - el hecho de que lo político se conforme antes como una amenaza que como una promesa de sentido para la vida humanareside para ella en la centralidad que adquieren las ideologías en su desarrollo moderno.

En el pensamiento de Hannah Arendt existe, pues, una constatación primera que sobrevuela toda consideración sobre la esfera política en la que, primariamente, se desenvuelve la vida humana: el fenómeno crucial que atraviesa el mundo contemporáneo es la toma de lo político por las ideologías, cuya expresión última y radical es la cancelación plena de la política misma por los totalitarismos del siglo XX. Frente a la noción común que hace descansar en los principios ideológicos lo genuinamente político, Arendt se atreve a desvelar que la pretensión de las ideologías modernas es la forja de una

\footnotetext{
${ }^{1}$ Sobre la idoneidad del término «totalitarismo» para referirse a la nueva forma de dominación política inaugurada en el siglo XX por el nacional-socialismo y el comunismo soviético, V. Arendt, $\mathrm{H}$; Los Origenes del Totalitarismo; op. cit. pp. 43-62.
} 
política que anule la política misma y, con ella, las facultades específicamente políticas que distinguen radicalmente la vida humana del resto de la vida animal sobre la tierra.

\section{Ideología y prejuicio}

La comprensión de las ideologías, así como de cualquier otro concepto político, exige rastrear las huellas y señales impresas a través de la historia hasta alcanzar las experiencias concretas de las que surgen, ya que el sentido de las ideas se encuentra, según nos dice Arendt, en aquellas experiencias y hechos a las que ofrecieron respuesta y marco de comprensión. Conforme a esto, Arendt indaga en los juicios a través de los cuales los hombres dan respuesta a las experiencias que conforman su vida en el mundo — siendo un juicio la comprensión en el lenguaje de una experiencia a la que de manera primaria se vincula- así como en los prejuicios — que provienen de juicios que han perdido ya el vínculo con las experiencias de las que surgieron y, por lo tanto, en vez de permitir una apertura hacia el mundo de los hechos y su contingencia, se erigen como protección ante el carácter en última instancia indeterminado y plagado de incertidumbre de la experiencia ${ }^{2}$ - . Todo juicio tiende, dejado de su mano y entregado al proceso natural de automatismo, a solidificarse en prejuicio, y es el esfuerzo deliberado de los hombres por comprender lo que les introduce en el «camino de vuelta» hacia las experiencias que le dieron principio y sentido.

Arendt afirma que las ideologías surgen históricamente como prejuicios que, en el seno de una crisis histórica crucial como fue la originada por la extrema tensión que la modernidad y sus tendencias introdujeron en el universo tradicional europeo - y que ocasionaron su destrucción acelerada a partir del siglo XVIII—

${ }^{2}$ Arendt, H., ¿Qué es la Política?; op. cit. pp. 52-59. No obstante, la autora no desecha de por sí el papel de los prejuicios, que forman una red de supuestos compartidos y acuerdos tácitos sobre las cosas sin la cual sería imposible la vida cotidiana; es imposible, nos dice, forjar un juicio sobre cada uno de los aspectos en los que se inserta y desenvuelve la vida en común de los hombres, y los prejuicios desempeñan la apreciable labor de ofrecer un marco de pre-comprensión en el que es posible la vida práctica en común y, también, la posterior enunciación de juicios genuinos sobre las cosas. 
se solidificaron extraordinariamente, desbordando el limitado ámbito al que pertenecían —el de alguna experiencia determinada — para extenderse a la totalidad de la experiencia e intentar así ofrecer, frente a los embates de la incertidumbre total que se apoderó de Europa, una explicación lógica, clara y también total de la realidad histórica y política. El carácter específico de las ideologías radica, con respecto al resto de prejuicios que pueblan la vida social y permiten su normal desenvolvimiento, en su extensión a la totalidad de la experiencia y, especialmente, a la de la experiencia política que, basada en la capacidad de formular y comunicar juicios a los otros -basada en opinar y persuadir- es corroída peligrosamente al verse sujeta al imperio del prejuicio. En las ideologías, de esta forma, los prejuicios cristalizan en cosmovisiones (weltanschauungen) ${ }^{3}$, de tal manera que, a diferencia del prejuicio común, que protege a los hombres de experiencias determinadas, las ideologías desbordan tal carácter limitado hasta aislar al hombre de toda realidad de hecho. Este carácter totalitario de las ideologías es lo que permite comprender la íntima continuidad entre ideología y totalitarismo político, de manera que facilita entender en su medida justa la decidida afirmación que realiza Arendt: los totalitarismos son la realización plena de las ideologías, el acabado producto de los imperativos lógicos que las constituyen ${ }^{4}$.

\footnotetext{
${ }^{3}$ Arendt, H., ¿Qué es la Política?; op. cit. p. 98. La noción de weltanschauung da cuenta de la influencia que el pensamiento de Jaspers pudo tener en el desarrollo de la teoría de Arendt acerca de las ideologías. Ya en un artículo de 1946 sobre las filosofías de la existencia, Arendt trató de esclarecer la importancia para Jaspers de las cosmovisiones como estructuras de pensamiento blindadas ante las «situaciones límite» que enfrentan a los hombres con la cuestión desnuda de la existencia. V. Arendt, H., "What is existential philosophy?», en Essays in Understanding» op. cit., p. 182.

${ }^{4}$ De manera semejante, Arendt afirma que toda ideología es por naturaleza totalitaria, ya que, en última instancia, su pleno acabado requiere de los medios desarrollados en el totalitarismo para instituir un dominio absoluto sobre la totalidad de los asuntos humanos. Por esta razón, afirma que, de las ideologías en pugna florecientes a partir del siglo XIX, sólo el racismo —realizado empíricamente por el régimen nazi alemán — y el comunismo — cuya existencia efectiva implantó el régimen comunista soviético- adquirieron real plenitud a través de los medios de terror y organización completa de la sociedad. Dado los límites del presente artículo, no podré tratar en profundidad de los hechos que añaden los totalitarismos a la lógica interna de las ideologías, pero, no obstante - y puesto que la autora subraya que la naturaleza íntima de las ideologías se manifiesta en su ejecución totalitaria- me ayudaré de algunas consideraciones tomadas de su análisis de los regímenes nazi y soviético. Sobre la co-pertenencia de ideología y totalitarismo: «La verdad es, más bien, que la verdadera naturaleza de todas las ideologías se revelaba sólo en el papel que la ideología desempeña en el aparato de dominación totalitaria». Los Orígenes del Totalitarismo; op. cit. p. 630.
} 
Si pretendemos comprender qué son las ideologías es preciso, de acuerdo con lo hasta aquí andado, remontar hasta las experiencias fundamentales que propiciaron su formación y determinar de qué modo estas experiencias son en ellas malentendidas o postergadas por otro tipo de exigencias, antes arraigadas en prejuicios emigrados a la esfera de lo político — como puede ser el de exigir de la realidad que se ajuste a la lógica de las ideas- que en juicios surgidos en la propia esfera y en su constelación de experiencias peculiares. La conmoción que denominamos modernidad significó, según supo apreciar la pensadora judía, un completo trastocamiento de las dimensiones que conformaron tradicionalmente la vida activa de los pobladores del mundo occidental y, a través de su expansión, del mundo entero. La desorientación resultante del trauma de la modernidad empujó a muchos a comprender aquellas esferas de la vida activa más marcadas por la incertidumbre y la inquietud a través de las categorías pertenecientes a las esferas determinadas por la seguridad y la corriente predecibilidad; de esta manera, la más frágil de las condiciones humanas, la vinculada a la capacidad política de acción, fue resueltamente reducida a categorías que, dando cuenta de otras esferas activas soportadas sobre la necesidad y la certidumbre, eran incapaces de conservar el carácter espontáneo, contingente y libre que en su autenticidad aquélla posee. Sólo así, a través del malentendido crucial de su condición característica, las ideologías procuraron reducir la acción —espontánea e incierta por naturaleza - al previsible decurso de los procesos automáticos; sólo así, por añadidura, trataron de asfixiar la contingencia de la política bajo las condiciones de irreversibilidad y certeza de la labor y el trabajo ${ }^{5}$, las dos restantes dimensiones que conforman la vida humana en su realidad activa.

${ }^{5}$ Sería excesivamente prolijo exponer aquí la compleja representación de las capacidades activas del hombre que lleva a cabo Hannah Arendt. Para un análisis pormenorizado me remito a su «La condición humana» y a mi trabajo "El concepto de ideología en Hannah Arendt». Bastará en este lugar con ofrecer la constelación de categorías convocadas por cada una de las distintas dimensiones de la humana «vita activa»:

Labor: el hacer de los hombres a través del cual aseguran la supervivencia y el mantenimiento del proceso vital. Es una experiencia regida por la necesidad y la coerción con que las demandas del organismo vivo han de ser satisfechas, y encuentra en el pensamiento su afinidad más profunda en el cálculo lógico y su desarrollo análogamente regido por la necesidad; además, se extrae de este ámbito la categoría sobresaliente de proceso, ya que la labor sólo puede ser pensada como un momento dentro del repetirse cíclico y necesario —elaboración/consumo— que es lo único que permanece. 


\section{El contenido de las ideologías}

\section{Libertad y proceso}

La imagen del hombre construida por las ideologías, según afirma Arendt, descansa sobre la exigencia de cambiar la condición humana, y ello, principalmente, en razón de la insatisfacción que produce la falta de ajuste entre las consecuencias de las acciones que los hombres llevan a cabo y los motivos conscientes que las inspiran ${ }^{6}$, ya que, en la acción, el actor nunca es dueño ni puede conducir a fin preconcebido lo que inicia. El sueño de llegar a ser auténtico señor de las propias acciones y actividades, de erradicar de la existencia humana la contingencia y la fragilidad — sueño ya presente desde los inicios de la especulación filosófica ${ }^{7}$ - es encumbrado como principio conductor de

Trabajo: a su través, los hombres construyen un mundo de objetos en el que habitar. Consiste en reificar, fabricar algo sólido y duradero capaz de resistir la fluidez e inconsistencia con que el proceso de la vida amenaza a todo lo que se sumerge en su seno. En el trabajo se distinguen sucesivamente el proyecto pensado - la imagen mental o idea antecedente de aquello que se quiere fabricar-, la búsqueda de los medios de los que se obtendrá la existencia plena de lo concebido y, por último, la ejecución "con las manos», que consigue la realización efectiva del fin proyectado. En la fabricación hay un comienzo y un fin definidos, por lo que el tránsito de uno a otro es previsible y puede ser sujeto a predicción. Aquí, por lo tanto, se da un criterio preciso para medir la idoneidad del producto: la adecuación de lo fabricado al eidos, es decir, el ajuste de la realidad al pensamiento y el primado de éste a la hora de establecer lo verdadero. En la fabricación la idea guía y "produce» la realidad, y no al contrario.

Acción: Esta actividad se asienta sobre el hecho exclusivamente humano de la pluralidad, ya que sólo en este caso el individuo no es la repetición de un patrón dado en la especie, sino que incorpora la unicidad que lo convierte en irremediablemente distinto con respecto a los demás. Actuar significa ejercitar la capacidad humana de comenzar algo, de tomar una iniciativa no determinada por causas precedentes. La acción constituye el modo en que a cada hombre le es dado aparecer ante los demás en el espacio público como distinto entre iguales, y por eso constituye la sustancia misma de este espacio y de la política, que da cuenta de lo que sucede en él. En tanto la acción se inserta en una trama de acciones ya iniciadas por otros -capaces ellos mismos de empezar series de acontecimientos imprevisibles y de interrumpir el curso de algo iniciado por los otros o variar las metas que el que lo inició se propuso- el irremediable sello de la acción reside en su carácter imprevisible, ya que el que actúa no puede controlar ni guiar el curso posterior de los acontecimientos que desencadena.

${ }^{6}$ Es decir, el hecho de que «los hombres son libres (...) mientras actúan, ni antes ni después, porque ser libre y actuar es la misma cosa». Arendt, H.; "¿Qué es la Libertad?», en Entre el Pasado y el Futuro; op. cit. p. 24.

${ }^{7}$ Queda fuera de los límites de este artículo el análisis que realiza Arendt sobre la raíz filosófica de los anhelos ideológicos. En particular, la pensadora judía localiza en Platón la traslación de 
las modernas construcciones ideológicas y su propuesta de sentido absoluto para la existencia humana. Por ello, contenido nuclear de las ideologías es la extirpación de todo aquello que, en el desarrollo de la acción, escapa al control humano - lo espontáneo que alborota su seno- con el fin de hacer de los asuntos humanos procesos domeñables ${ }^{8}$. En este sentido, toda ideología es un instrumento de abolición de la espontaneidad humana y la libertad que en ella se muestra.

Arendt, al desentrañar la reformulación ideológica de la condición humana, presta especial atención al destino deparado a la libertad propia de la acción, que deja de tener cabida en una reconstrucción que apela a experiencias controlables y previsibles - lo que incluye entonces la supresión de la acción en tanto tal y su suplantación por comportamientos extraídos de esferas ajenas - como forma de eliminar la fuente de la indeterminación que pueda afectar a lo comenzado por los hombres.

La principal raíz de la inseguridad y la falta de dominio que distinguen a la acción de otras experiencias se revela, según afirma Arendt, sobre el hecho de la pluralidad humana. La acción es, según afirma, la única actividad que los hombres no pueden realizar en soledad; el hecho de que las acciones que

las categorías de la fabricación — como paradigma de una actividad atenida a desarrollo predecible y cierto- a la esfera de los asuntos humanos, la política y la acción; no obstante, y de ahí la imposibilidad de que la filosofía se constituyera en ideología hasta bien entrada la modernidad, la filosofía en su conjunto siempre mantuvo una aprensión de principio ante el intento de intervenir en los asuntos públicos y, según Arendt, sólo se preocupó de no ser dañada por ellos; de este modo, el mismo Platón no concibió que la realidad mundana pudiera ser modelada perfectamente de acuerdo con el pensamiento, ya que siempre contempló en la materia indocilidad y resistencia ante el dictado de las ideas. Sólo en el siglo XIX, cuando Hegel introduce la idea en el mismo decurso de la realidad del mundo y en la historia, se hará posible el salto de la filosofía a la ideología, que será sucintamente anunciado por Marx al afirmar, en sus tesis sobre Feuerbach, que la tarea del filósofo no es ya comprender el mundo, sino cambiarlo.

Para un desarrollo más amplio de las semillas que la tradición filosófica donó para que germinaran finalmente en las ideologías contemporáneas, véase mi trabajo "El concepto de ideología en Hannah Arendt».

${ }^{8}$ El terror, como anulación práctica de la espontaneidad humana, es contemplado por Hannah Arendt como el centro del empeño totalitario por realizar efectivamente los postulados ideológicos: "La dominación totalitaria, empero, se orienta a la abolición de la libertad, incluso a la abolición de la espontaneidad humana en general (...)». Arendt, H.; Los Origenes del Totalitarismo; op. cit. p. 550. 
iniciamos se introducen en una trama imprevisible de acciones iniciadas por otros imprime en ellas el carácter peculiar de incertidumbre que les es propio. Si sólo existiera un hombre sobre la tierra, su dominio sobre lo que inicia podría ser idealmente completo, cosa que no ocurre cuando los otros poseen también la iniciativa de poner cosas en marcha. Las ideologías, como forma de doblegar el discurrir de los asuntos humanos a la seguridad de lo previsible, suplantan definitivamente esta libertad que surge de la pluralidad y convivencia de los hombres distintos — tiznada de radical incertidumbre- por el modelo de libertad del hombre solo, del individuo único que no ha de temer que sus actuaciones se vean desviadas por las de los otros. Las ideologías no dejan de hablar de «libertad», pero redefinen de modo tal su consistencia que, a su través, se anula a la vez la libertad específicamente humana perteneciente a su capacidad de actuar. Cristaliza de esta manera el viejo prejuicio de adoptar como única libertad deseable la identificada con la omnipotencia, esto es, la distinguida como capacidad del actor de controlar de principio a fin aquello que lleva a cabo, mientras se destierra la genuina forma de libertad basada en la espontaneidad, por naturaleza unida siempre al desconocimiento de consecuencias; las ideologías, en su reestructuración de las experiencias humanas, universalizan entonces la libertad propia del ámbito del trabajo y la fabricación - la libertad del artesano o demiurgo que fabrica, sin la intromisión de otros, lo que previamente ha proyectado- con el fin de expulsar de los asuntos de los hombres lo inseguro que impregna la acción emprendida entre los otros. De esta manera, las ideologías llevan a término la visión de una unidad esencial de los hombres y conciben que éstos se pueden integrar sin resto en un sujeto único — ya sea la «humanidad», la «raza» o el "proletariado»— que, frente al caos de la libertad de cada uno, sea el sujeto verdaderamente libre, capaz de «hacer» sin las distorsiones provenientes de la presencia de otros actores ${ }^{9}$. La respuesta ideológica a las perplejidades que emanan de la incontrolable libertad de los individuos en la acción descansa en la atri-

\footnotetext{
${ }^{9}$ «(...) la convicción de que la libertad del hombre debe ser sacrificada al desarrollo histórico cuyo proceso puede ser obstaculizado por el hombre únicamente si éste actúa y se mueve en libertad. Esta concepción es común a todos los movimientos políticos específicamente ideológicos. (...) lo decisivo es que la libertad no se localice ni en el hombre que actúa (...) ni en el espacio que surge entre los hombres, sino que se transfiera a un proceso que se realiza a espaldas del hombre que actua, y que opera ocultamente, más allá del espacio de los asuntos públicos». Arendt, H.; ¿Qué es la Política?; op. cit. p. 72.
} 
bución al todo del exclusivo carácter de actor, y, por lo tanto, Arendt percibe como contenido característico de las ideologías la ley de disolución del individuo y sus intereses en el "proceso o progreso de la especie», la pérdida de relevancia de lo individual debido a que sólo puede manifestarse como interferencia ante la libertad del todo ${ }^{10}$. El coste de la libertad postulada por las ideologías —identificada con la omnipotencia del hombre - reside entonces en la superfluidad de los hombres, en la noción de que es necesaria su organización estricta para «dominar a los seres humanos hasta el grado en que pierdan, junto con su espontaneidad, la impredecibilidad específicamente humana de pensamiento y acción ${ }^{11}$. No otra cosa es, según Arendt, la empresa totalitaria de «fabricar» una sociedad estrictamente unitaria, ya que la forja de un sujeto «total» habría de ser el único modo de realizar una libertad entendida como la soberanía sobre la totalidad de lo que los hombres hacen ${ }^{12}$. Por esta razón reina en las sociedades totalitarias la fascinación por lo unitario, por la homogeneidad de las masas coordinadas y los espectáculos de exhibición de multitudes uniformes, por la Gleichschaltung, por la sujeción a una sola voluntad compartida que convierte a los individuos aglutinados en un solo cuerpo ${ }^{13}$.

El sujeto libre postulado por las ideologías se muestra como el resultado de la inmersión de los individuos separados en un proceso total en el que cada uno adquiere una función precisa y sólo constituye un momento necesariamente irrelevante ante la grandeza del todo. Este proceso que borra cualquier separación o diversidad entre individuos puede conservar en cada ideología concreta una naturaleza peculiar, pero determina la nota característica del pensamiento ideológico, que es el pen-

${ }^{10}$ Arendt, H.; Essays in Understanding; op. cit. pp. 340- 343.

${ }^{11}$ Ibídem, p. 350.

${ }_{12}$ "Lo que liga a estos hombres es una firma y sincera fe en la omnipotencia humana. Su cinismo moral, su creencia de que todo está permitido, descansan en la sólida convicción de que todo es posible». Arendt, H.; Los Orígenes del Totalitarismo; op. cit. p. 29.

${ }_{13}$ «El poder, tal como es concebido por el totalitarismo, descansa exclusivamente sobre la fuerza lograda a través de la organización. De la misma manera que Stalin concibió a cada institución (...) sólo como una "correa de transmisión que conecta al partido con el pueblo» (...) Hitler, en fecha tan temprana como 1929, vio la "grandeza" del movimiento en el hecho de que sesenta mil hombres "han constituido exteriormente casi una unidad, que realmente estos hombres son uniformes no sólo en ideas (...) descubriréis ...cómo cien mil hombres de un movimiento se convierten en un solo tipo"” (comillas de la autora). Arendt, H.; Los Origenes del Totalitarismo; op. cit. p. 565. 
samiento procesual mismo propio de la experiencia humana de la labor y la pervivencia de las funciones orgánicas del cuerpo ${ }^{14}$; tanto da, afirma Arendt, pensar en el proceso de la Naturaleza o de la Historia - como hacen respectivamente el nazismo y el comunismo- ya que en ambos casos lo verdaderamente relevante es el pensamiento de una realidad total que adquiere los atributos de un sujeto y excluye a los individuos existentes del papel de actores para condenarlos al de instrumentos de realización. En el seno de este proceso, entonces, el hombre particular es concebido únicamente como función, como célula, y, más específicamente, es definido bien como obstáculo, bien como facilitador de la marcha del proceso, como catalizador o agente patógeno. Ésta es, entonces, la única alternativa capaz de caracterizar a los hombres de acuerdo con las ideologías: víctimas del proceso o ejecutores ${ }^{15}$, lo que, a su vez, apunta a otra de las señas que las distinguen de otras formas de pensamiento: la articulación de la realidad en torno a un sistema de oposiciones binario, la división estricta de la humanidad en dos polos irreconciliables e inconfundiblemente distinguidos a los que el proceso reserva funciones y destinos también estrictamente separados. Es fundamental en esta división estricta de la humanidad en dos polos opuestos la concepción de que es la esencia lo que hace pertenecer a los hombres a uno u otro "partido", y no lo que hacen y dicen; los hombres son, no actúan o hablan. El individuo puede no saber qué es, pero la penetración en el conocimiento de la realidad lograda a través de la cosmovisión ideológica lo determina categóricamente aunque los hechos «aparentemente» lo contradigan ${ }^{16}$.

${ }^{14}$ Convertir la realidad en proceso supone asimilarla a la experiencia humana de la labor, el proceso biológico de mantenimiento de la vida; supone, por lo tanto, extender la férrea determinación y necesidad de las exigencias orgánicas a la realidad toda y, dentro de ella, a la convivencia mundana y política de los hombres. Frente a la indeterminación de la acción, el hacer humano es aquí entendido como simple labor o metabolismo del cuerpo social.

15 "According to this law, they may today be those who eliminate the "unfit races and individuals" or the "dying classes and decadent people» and tomorrow be those who, for the same reasons, must themselves be sacrificed [De acuerdo con esta ley, (los hombres) pueden ser hoy los encargados de eliminar a las «razas e individuos inadaptados» o a las «clases sociales agonizantes y la gente decadente» y mañana ser ellos mismos los que, por las mismas razones, han de ser sacrificados (comillas de la autora]». Arendt, H.; Essays in Understanding; op. cit. p. 349.

${ }^{16}$ Hannah Arendt refiere la categoría soviética de "culpable objetivo", es decir, del individuo que, «sin saberlo», y aunque subjetivamente sea simpatizante del régimen, es considerado enemigo "del pueblo" por ser burgués, kulak, ucraniano... "Merely belonging to a "dying" class made one "objectively" guilty, without having "subjectively" comitted any crime whatsoever [Sólo pertenecer a una clase "agonizante" hacía a uno "objetivamente" culpable, sin haber "subjetivamente" cometido crimen ninguno] (comillas de la autora). Arendt, H.; "The eggs speak up», en Essays in Understanding; op. cit. p. 276. 
Insertados los hombres en un proceso concebido como el metabolismo vital de un súper-sujeto, el interés por el mundo, las cosas y su substancia es sustituido por el exclusivo interés por el proceso que conduce a su producción, lo que explica el desapego mundano - la «mentalidad no mundana»- que muestran los movimientos ideológicos ${ }^{17}$, así como su emancipación de la realidad presente - que puede ser suprimida o sacrificada — ante la perspectiva de lo que el proceso ha de realizar. La perspectiva profética del fin del proceso invita a devaluar todo lo que constituye el estado presente del mundo y a utilizar cualquier medio para facilitar el advenimiento de la realidad completa anhelada; por esta razón, Arendt incluye en su caracterización de las ideologías la aceptación de la violencia y la destrucción de lo existente como medios privilegiados de intervención política, ya que son los que más fácil y rápidamente pueden alcanzar los fines que se proponen. El desprecio de la ley jurídica, ya que sólo se muestra como obstáculo «formal» para la consecución definitiva de cualquier fin, es, consecuentemente, compartido por las ideologías ${ }^{18}$.

\section{Realidad y lógica}

Arendt considera que el pensamiento sólo alcanza la condición de ideología cuando contiene la certeza de haber logrado descubrir la clave explicativa completa de la realidad y su discurrir histórico ${ }^{19}$; una proposición aislada puede ser verdadera o falsa, pero no es en ningún caso «ideológica» si no es por la pertenencia a una cosmovisión en la que se da por definitivamente resuelta la clave que da cuenta de la totalidad de los fenómenos y sucesos que afectan a los hombres y al mundo que habitan ${ }^{20}$. De esta manera, el racismo por sí solo, el deseo de revolución o el antisemitismo, no son para Hannah Arendt ideologías, pero

\footnotetext{
${ }^{17}$ Arendt, H.; La Condición Humana; op. cit. p. 284.

${ }^{18}$ Arendt, H.; Los Orígenes del Totalitarismo; op. cit. pp. 619 y ss.

19 «Esta fascinación [la causada por Hitler] (...) se apoyaba desde luego (...) en sus pseudoautorizados juicios sobre todo lo divino y lo humano y en el hecho de que sus opiniones - tanto si se referían a los efectos perjudiciales del hábito de fumar o a la politica de Napoleón- siempre encajaban en una ideología que lo abarcaba todo». Ibídem, pp. 431-432.

${ }^{20}$ "I call all ideologies in this context "isms" that pretend to have found the key explanation for all the misteries of life and world. [En este contexto, llamo a todas las ideologías "ismos" que pretenden haber encontrado la clave explicativa de la totalidad de los misterios de la vida y el mundo. (comillas de la autora)]. Arendt, H.; Essays in Understanding; op. cit. p. 349.
} 
se convierten en tales en el momento en el que se presentan como la explicación irrefutable de la totalidad de la historia humana, ya sea contemplando su curso como manifestación de una conspiración judía o describiendo todo acontecimiento como fruto de la lucha eterna y necesaria de las razas por el predominio; de la misma forma, el comunismo o el socialismo se convierten en ideologías en tanto pretenden que todo lo ocurrido en la historia es producto de la "lucha de clases», y afirman haber descubierto con ella la ley que comprende todo acontecimiento y dicta su devenir universal y necesariamente ${ }^{21}$. Lo crucial de las explicaciones «totales» que ofrecen las ideologías es su desvinculación de los hechos de la experiencia, su emancipación completa de la realidad fáctica, ya que postulan como principio de toda explicación válida la reducción de lo existente a categorías pensadas que adquieren carácter axiomático y, necesariamente, son contempladas como causa de lo que ocurre; de este modo, al distinguir estrictamente los fenómenos aparentes de una causa subyacente revelada sin resto por la idea, devalúan la apariencia a mero caso sólo poseedor de realidad en tanto se esconda en él aquél motor profundo de lo real. En este sentido, la ideología heredó el recelo filosófico hacia las apariencias, convirtiendo en activa —en última instancia a través del terror y la aplicación del poder del estado— la convicción hegeliana de que si un hecho no corresponde a la idea, es el hecho el que ha de doblegarse a ésta ${ }^{22}$.

La pretensión ideológica de haber encontrado el sentido oculto y absoluto de todo acontecimiento revela la fascinación que se desprende del tipo de explicaciones absolutas enunciadas por la ciencia moderna. La ideología, de modo característico, supone la introducción de las categorías de las ciencias naturales en la explicación del mundo humano, y la consiguiente sujeción de éste al determinismo y necesidad que la ciencia moderna introdujo en la explicación del universo natural ${ }^{23}$. El gran poder persuasivo de las ideologías refiere en

${ }^{21}$ Ibídem, pág. 349.

${ }^{22}$ Para Arendt, el terror no es más que el medio efectivo de someter lo real al sistema de ideas propugnado en las ideologías, obteniendo así una realidad perfectamente adecuada a su rígida consistencia lógica. Sólo así se resuelve la distancia entre el mundo previsible y cierto de la ideología y la incertidumbre del mundo existente: obligando violentamente a éste a adecuarse al modelo ofrecido por aquél. Ibídem, p. 350.

${ }^{23}$ Arendt se refiere en numerosas ocasiones al fundamento "científico» que justificó el programa nazi de exterminio en las cámaras de gas, así como su misma articulación y desenvolvimiento técnicos y supuestamente asépticos: «Perhaps they had forgotten the climate of public opinion in which 
muchos casos a su uso de «verdades científicas» presentadas como irrebatibles principios de la realidad humana. Toda ideología, afirma Arendt, se procura un arsenal de proposiciones científicas para dotarse del prestigio y la contundencia propios de lo no opinable, y así ganar para su causa a las masas anhelantes de orientación y rumbo. El prestigio que deslumbra a los ideólogos proviene de la aparente irrefutabilidad de la ciencia, de su solidez y coherencia internas que reducen la proliferación mundana de contingencias y avatares desordenados a unidad y consistencia lógica. Un mundo que respondiera plenamente a los principios de ordenación actuantes en las ciencias naturales (newtonianas) habría desterrado de su seno toda la imprevisibilidad y contingencia que las ideologías contemplan como mal radical de la existencia humana, por lo que sustancian como imperativo el ideal, adoptado como científico por buena parte de las ciencias sociales, de amoldar a los hombres a un mundo controlable ${ }^{24}$. Por ello, las ideologías procuran adoptar una forma «científica» ${ }^{25} \mathrm{y}$

they killed. Perhaps they never cared to know it, since they felt, wrongly, that their "objective and scientific" attitude was far more advanced than the opinions held by ordinary people [Quizás habían olvidado el clima de opinión pública en que mataron. Quizás nunca les importó conocerlo, dado que sentían, erróneamente, que su "objetiva y científica" actitud era mucho más avanzada que las opiniones mantenidas por la gente ordinaria (comillas de la autora)]. Arendt, H.; Eichmann and the Holocaust; op. cit. pp. 51-52.

${ }^{24} \mathrm{El}$ ideal de las ciencias sociales, por lo tanto, es inmensamente cercano al asumido por las ideologías, lo que Arendt identifica en la misma voluntad de hacer imposible la espontaneidad a través de la organización social y la construcción de una realidad en la que nada escape a la programación funcional. En un ensayo dedicado a Dewey, que había publicado una obra en la que hacía gravitar los problemas humanos en torno a la falta de organización científica y el primado del «laissez-faire», Arendt desarrolla esta similitud entre ciencias sociales e ideología; además, otro artículo de la autora se dedica al análisis de los campos de concentración y exterminio como laboratorios donde poner en funcionamiento las tesis de los científicos sociales sobre una sociedad en la que haya desaparecido el poder de incertidumbre de la libertad humana. Arendt, H.; «The ivory tower of common sense» $\mathrm{y}$ "Social science techniques and the study of concentration camps», en Essays in Understanding; op.cit. pp. 194-197 y 232-248.

${ }^{25}$ En el caso del nazismo, apelando a la «lucha por la vida» y la supervivencia del más apto darwinianas, en el caso del comunismo aceptando como axiomática la categoría científica del socialismo marxista y la deducción de la realidad a partir de sus categorías básicas. La dislocación ideológica de lo real es aquí tangible en la sustitución del sentido común — que permite la convivencia política en un mundo compartido- por las categorías propias de las ciencias naturales y el cálculo lógico: «(...) the peculiar and ingenious replacement of common sense with stringent logicality, which is characteristic of totalitarian thinking, is particularly noteworthy $[(. .$.$) la peculiar e ingeniosa sus-$ titución del sentido común por la rigurosa lógica, que es característica del pensamiento totalitario, es particularmente digna de mención]». Arendt, H.; Essays in Understanding; op. cit. p. 317. 
ofrecer una visión del mundo articulada en torno a la coherencia y consistencia que, inexistentes en la experiencia mundana de lo real, sólo existe en las construcciones mentales y, en su grado máximo, en el cálculo lógico. La ideología es, como consecuencia, la fidelidad a la lógica de las ideas a la hora de explicar y comprender el mundo, en vez de a los hechos mismos que lo inte$\operatorname{gran}^{26}$, y, por ello, la narración que proponen del transcurso de la realidad hace depender los acontecimientos de las leyes que guían la exposición lógica de las ideas. La perfección de esta lógica — tal y como la autora la percibe en los estados totalitarios - implica, de esta manera, la sustitución de la realidad fenoménica y su acontecer incierto por la certeza propia de los sistemas deductivos, por sus extremadas coherencia y falta de contradicción. La imagen del mundo que de esto se desprende está dominada por la seguridad y previsibilidad que reina en el desarrollo de las deducciones, por lo que la realidad de lo real deja de estribar en la existencia, para mostrarse en la consistencia; sólo es real lo que obedece a la lógica del sistema, mientras que todo hecho que escapa a su imperio es, o bien obligado a encajar en «su idea», o bien simplemente expulsado de la realidad como mera apariencia o fenómeno carente de significado ${ }^{27}$. La primacía de la idea sobre los hechos determina el desprecio hacia la existencia que muestran las ideologías, de tal modo que su finalidad no se dirige a comenzar hechos, a introducir lo nuevo en el discurrir del mundo, sino a la supresión de la realidad presente como manera de que llegue a mostrar su absoluta conformidad con la idea, lo que es decir: a instaurar definitivamente una realidad en la que sea imposible lo nuevo, lo no deducible ${ }^{28}$.

${ }^{26}$ Arendt, H.; Los Orígenes del Totalitarismo; op. cit. p. 628.

${ }^{27}$ El lenguaje propio de las ideologías, según Arendt, no se destina a la revelación de lo real, sino a su reformulación de acuerdo con las exigencias lógicas del sistema; así, el asesinato de los deficientes mentales emprendido por el régimen nazi — y denominado «programa de eutanasia»no contenía la categoría lingüística de «asesinato» ni ninguna parecida; el hecho mismo era obligado a adecuarse a la lógica del programa mediante su subsunción en categorías lingüísticas separadas de su realidad como hecho: "garantizar una muerte compasiva». Arendt, H.; Eichmann and the Holocaust; op. cit. p. 50.

${ }^{28}$ Como exponente de adoración hacia la lógica frente a la imagen sensible de las cosas, Arendt cita discursos y conversaciones de Hitler y Stalin: "Uno se jactaba de su supremo don del "frío razonamiento" (Hitler), y el otro de su "implacable dialéctica" y procedian a empujar a las implicaciones ideológicas hacia extremos de consistencia lógica (...)». Arendt, H.; Los Orígenes del Totalitarismo; op. cit. p. 631. 
A través de un novedoso método de demostración ${ }^{29}$ —real es aquello que carece de indeterminación y se inserta sin resto en una explicación del mundo sin lagunas - el pensamiento ideológico se emancipa de la realidad al mostrar a los hombres una realidad "más verdadera» sólo perceptible a su través, y ante la cual cualquier experiencia aparece como un elemento irrelevante y desvinculado de la esencia del mundo ${ }^{30}$. El sentido común —entendido como órgano de percepción de un mundo común - es sustituido por la lógica, y Arendt determina la crucial diferencia entre uno y otro modo de aprehender la realidad: mientras el sentido común depende de la existencia de hechos y necesita de la presencia de otros, la lógica es independiente de cualquier hecho y refiere a la soledad del pensamiento consigo ${ }^{31}$. La lógica, en tanto también es algo común a todos los hombres, ofrece en las ideologías un plausible sustituto del sentido común, pero su primacía cancela el espacio público comunitario en el que pueden darse la acción, la política y la indeterminación surgidas de su ejercicio $^{32}$.

La gran amenaza que, para Arendt, adelanta la ideología es la conversión de la lógica en una potencia productiva, la exportación a la realidad de lo que es propio de la interioridad del pensamiento, ya que, según afirma, las ideas, cuando desplazan a la existencia como centro de lo real, se desatan furiosas y criminales en el intento de crear un mundo hecho a su imagen y semejanza, lo que significa la destrucción del mundo existente y compartido. La macabra hegemonía de la lógica que instauraron los totalitarismos — que, según Arendt, fueron producto de tomarse «en serio» las consecuencias lógicas de las premisas ideológicas $^{33}$ - se volcaron consecuentemente en la destrucción del mundo existente,

${ }^{29}$ Ibídem, p. 631.

${ }^{30}$ Arendt refiere la categoría de «delito posible», así como la «detención preventiva» consecuente, como ejemplo de razonamiento que toma como real aquello que se deduce de las premisas ideológicas. En ambos casos, la condición del crimen a castigar no descansa en los hechos que se evaporan y se convierten en irrelevantes una vez desatada la deducción- sino en las consecuencias que se infieren de las premisas lógicas que fundan el sistema. Ambas categorías fueron ampliamente utilizadas en los sistemas penales nazi y soviético, y en ambos casos se procedió a deducir «hechos» de axiomas o principios lógicos. Arendt, H.; Los Orígenes del Totalitarismo; op. cit. p. 576.

${ }^{31}$ Arendt, H.; «Understanding and politics», en Essays in Understanding; op. cit. p. 318.

32 Ibídem, p. 318.

${ }^{33}$ V. Arendt, H.; «Ideología y terror: una nueva forma de gobierno», en Los Orígenes del Totalitarismo; op. cit. pp. 617-641. 
de sus tradiciones, y en la instauración de un mundo «nuevo» poblado por «hombres nuevos ${ }^{34}$.

\section{Verdad y falsedad}

Una radical novedad de la ideología se cifra, según Hannah Arendt, en el abandono de la tradicional noción del pensamiento como comprensión — como theoria - y su transformación — según el modelo que guía a los procesos de fabricación - en una doctrina para hacer ${ }^{35}$; la lógica adquiere así, liberada de su constreñimiento a los límites mentales, el carácter de potencia productiva volcada en la construcción de una realidad definitivamente sometida a sus principios. De acuerdo con esta profunda metamorfosis sufrida por el pensamiento y su papel en la experiencia humana, también el concepto de verdad había de padecer una redefinición igualmente profunda con el fin de prestarle sitio como potencia activa. En rigor, según Arendt, las ideologías se separan absolutamente del sentido común al dejar de prestar atención a la distinción entre lo verdadero y lo falso, al adoptar la perspectiva nihilista que equipara los hechos a las opiniones —en la inconsistencia y carencia de fundamento que la tradición filosófica contemplaba en éstas- y arrojar entonces a la verdad de hecho al campo de lo opinable y relativo ${ }^{36}$. La renuncia a dar relevancia a la existencia, mantenida — con algunas excepciones- por la tradición filosófica, y marcadamente opuesta al sentido común, es conducida al rango de absoluto por las ideologías, que no aceptan como criterios el de la verdad o falsedad de hecho, sino exclusivamente el de la consistencia lógica. La ideología completa, a través de una inversión, la vieja convicción filosófica de que la verdad se identifica con «la realidad», más no entendida ésta de ningún modo como el aparecer de las cosas mismas o su desvelamiento en la existencia contingente, sino como la adecuación a la «consis-

\footnotetext{
34 "Ideologically speaking, nazism begins with no traditional basis at all, and it would be better to realize the danger of this radical negation of any tradition (...) [Ideológicamente, el nazismo da comienzo sin apoyarse en tradición ninguna, y sería deseable tomar conciencia de esta radical negación de toda tradición (...)]». Arendt, H.; Essays in Understanding; op. cit. p. 108.

35 "Toda ideología completa ha sido creada, continuada y mejorada como arma política y no como una doctrina teórica». Arendt, H.; Los Orígenes del Totalitarismo; op. cit. p. 256.

${ }^{36}$ "(...) sin la elite y su incapacidad artificialmente inducida para comprender los hechos como hechos, para distinguir entre la verdad y la falsedad, el movimiento nunca podría moverse en la dirección que requiere la realización de su ficción». Ibídem, p. 526.
} 
tencia de un orden subyacente del mundo» ${ }^{37}$; Arendt expone cómo la aceptación de que «la verdad es la realidad» conduce al axioma ideológico de que, si podemos «fabricar» la realidad — poner en el mundo productos mentales que funcionen de acuerdo con los atributos lógicos de la realidad- entonces la verdad no reside en la revelación y esplendor de las cosas aparte del dominio humano, sino que puede ser producida por la actividad del hombre. La verdad, según los esquemas ideológicos, es algo que el hombre puede hacer; por ello, Arendt concluye que la cuestión de la verdad o falsedad de la ideología pierde todo sentido, ya que el criterio que la convierte en válida es el de la posibilidad de que lo postulado llegue a ser real, se inserte en un proceso en el que adquiera los atributos de la realidad. Las ideologías continúan utilizando el término "verdad», pero vaciado de todo su contenido experiencial y referido exclusivamente al poder del hombre omnipotente — el hombre organizado — de hacer lo que expresan las ideas; las ideologías se presentan como «verdaderas» por el hecho de que, sean sus proposiciones verdaderas o no - lo que es indiferente- pueden llegar a serlo a través de la actividad consciente y laboriosa del hombre ${ }^{38}$. La ideología se asienta, entonces, en la confianza ciega de que lo verdadero es fruto de la fabricación, y, por esa razón, es en las sociedades totalitarias, donde se han liberado de todo límite las capacidades humanas productivas, donde se llega a fabricar como verdadera la ficción ideológica, que adquiere realidad al ser asumida como tal en el comportamiento coordinado de las masas y funcionar, entonces, como real ${ }^{39}$. En el caso nazi, por ejemplo, la autora muestra cómo la «verdad» ideológica que definía a los judíos como «subhumanos», y que antes de la hegemonía nazi no respondía a «las apariencias», se «realizó» a través del destierro y de la construcción de los campos de concentración y exterminio en los que los judíos fueron hacinados y

${ }^{37}$ Arendt, H.; Essays in Understanding; op. cit. pp. 354-355.

${ }^{38}$ Según defiende Arendt, la fe en la omnipotencia humana se expresó de modo definitivo en los campos de exterminio, en los que se hace patente la operatividad del principio ideológico de que, aparte de la consideración de la verdad o falsedad, todo es posible. V. Arendt, H.; «Social science and concentration camps», Ibídem, especialmente p. 236.

${ }^{39}$ "Certainly, the impact of an everyday life wholly permeated by Nazi doctrines and practices was not easy to resist. The position of an anti-nazi resembled that of a normal person who happens to be thrown into an insane asylum where all the inmates have exactly the same delusion: It becomes dificult under such circunstances to trust one's own senses [Ciertamente, el impacto de una vida cotidiana completamente permeada por las doctrinas nazis no era fácil de resistir. La posición de un antinazi se asemejaba a la de una persona normal arrojada en un manicomio donde todos los internos padecen los mismos delirios. Bajo esas circunstancias, se hace difícil confiar en los propios sentidos]». Ibídem, p. 259. 
devaluados a la literal condición de seres subhumanos ${ }^{40}$; paralelamente, la verdad ideológica asumida por el comunismo al defender que las clases sociales estaban condenadas por la historia a la "desaparición" y anegación en la sola especie humana, identificada con el proletariado, no refería una cuestión de hecho, sino de poder de realización. Tal convicción fue demostrada como verdadera en el exterminio stalinista de las «clases agonizantes» —el asesinato de los «kulaki», el despojamiento de las "clases burguesas»— que hizo de la sociedad soviética, en efecto, una sociedad sin clases de tal naturaleza ${ }^{41}$. En tanto todo se puede fabricar, la distinción entre lo verdadero y lo falso pierde significado ${ }^{42}$. La «verdad» de las proposiciones ideológicas adquiere así consistencia de "verdad profética», no de hecho; la verdad del axioma nazi de que la raza es la cualidad determinante en el lugar que ocupan los hombres en el mundo y la sociedad no se fundaba en que eso fuera un hecho, sino en que alguna vez la realidad se manifestaría y mostraría la adecuación de tal postulado a su trama profunda; así, a través de la actividad y la organización totalitarias, «llegó a ser verdadero» que la raza determinaba a los hombres al colocarlos en un lugar u otro de la sociedad — por ejemplo, al ario en el poder, al judío en las exclusas concentracionarias del sistema ${ }^{43}$.

\section{Bibliografía}

ARENDT, H. (1994). Essays in understanding, 1930-1954. Formation, exile and totalitarianism - New York: Schocken Books.

${ }^{40}$ Arendt, H.; «The image of hell»; Ibídem, pp. 197-206.

${ }^{41}$ Arendt, H.; «Una sociedad sin clases», en Los Orígenes del Totalitarismo; op. cit., especialmente pp. 448-453.

42 "(...) that we do not have to wait until reality unveils itself and shows us its true face, but can bring into being a reality whose estructures will be known to us from the beginning because the whole thing is our product. [ (...) que no tenemos que esperar hasta que la realidad se revele por sí misma y nos muestre su auténtico rostro, ya que podemos traer a existencia una realidad cuyas estructuras nos serán familiares desde un principio porque son producidas por nosotros. (...) ]». Arendt, H.; Essays in Understanding; op. cit. p. 354.

${ }^{43}$ También en el caso del comunismo acierta a identificar Arendt esta concepción de «verdad profética», presente ya como teoría, por otro lado, en Marx: (...) Hegel proyectó su visión histórica del mundo sólo hacia el pasado, dejando que se extinga en el presente como su consumación, mientras que Marx la proyectó "proféticamente» en la dirección contraria, hacia el futuro, y entendió el presente tan sólo como un trampolín. Arendt, H.; La Promesa de la Política; op. cit. p. 107. 
- (2006). Los orígenes del totalitarismo / Traducido por Guillermo Solana - Madrid: Alianza Editorial.

- (2005).La condición humana / traducido por Ramón Gil Novales - Barcelona: Paidós.

- (2008). La promesa de la política / Traducido por Eduardo Cañas y Fina Birulés Barcelona: Paidós.

- (1997). ¿Qué es la política? / Traducido por Rosa Sala Carbó - Barcelona: Paidós / I.C.E. Universidad Autónoma de Barcelona.

- (2007). Karl Marx y la tradición del pensamiento occidental / Traducido por Agustín Serrano de Haro - Madrid: Ediciones Encuentro.

- (2003). Entre el pasado y el futuro. Ocho ejercicios sobre la reflexión politica I Traducido por Ana Poljak - Barcelona: Ediciones Península.

- (2004). Sobre la revolución / Traducido por Pedro Bravo - Madrid: Alianza Editorial.

- (2005). Eichmann and the holocaust - London: Penguin Books.

- (2005). Sobre la violencia / Traducido por Guillermo Solana - Madrid: Alianza Editorial.

- (1977). The life of the mind. The groundbreaking investigation on how we think - New York: Harcourt, Inc.

Recibido: $13 / 10 / 2010$

Aceptado: 22/10/2011 
